\title{
GERMINAÇÃO E SANIDADE DE SEMENTES DE Bauhinia variegata ${ }^{1}$
}

\author{
Adriana Martinelli-Seneme ${ }^{2}$, Edilberto Possamai ${ }^{3}$, Lucimeris R. Schuta ${ }^{3}$ e Silvelena Vanzolini ${ }^{4}$
}

\begin{abstract}
RESUMO - As bauínias são consideradas pioneiras tardias na escala de sucessão vegetal, pois têm crescimento moderadamente rápido. Podem ser utilizadas como planta forrageira, ornamental, para papel e celulose, madeira serrada e roliça e também para recuperação de áreas degradadas. Buscando-se alternativas por meio de métodos de escarificação, para uma germinação rápida e uniforme, sementes de Bauhinia variegata foram submetidas aos seguintes tratamentos pré-germinativos: escarificação mecânica com lixa 220; imersão em água quente a $80^{\circ} \mathrm{C}$; imersão em água fria a $10^{\circ} \mathrm{C}$ durante $2 \mathrm{~h}$; corte com tesoura na região oposta à micrópila; imersão em ácido sulfúrico concentrado por 5 min seguida de lavagem em água corrente; e imersão em ácido sulfúrico concentrado por $20 \mathrm{~min}$, seguida de lavagem em água corrente. Em seguida, as sementes foram colocadas para germinar em caixas plásticas tipo gerbox em substrato de vermiculita sob temperatura constante de $30^{\circ} \mathrm{C}$, com avaliações aos sete e 14 dias, e semeadas em bandejas de isopor em areia em casa de vegetação. Avaliaramse, em casa de vegetação, a porcentagem final de emergência aos 32 dias após a semeadura e o índice de velocidade de emergência. Foi realizado, ainda, o teste de sanidade (Blotter Test) com 400 sementes, pelo método de papel-filtro (Blotter test). Para o teste de germinação e índice de velocidade de emergência foram utilizadas cinco subamostras de 30 sementes de cada tratamento, sendo o experimento conduzido em delineamento inteiramente casualizado, em comparação com as médias pelo teste de Tukey $(\mathrm{P}>0,05)$. Constatou-se que a escarificação mecânica (lixa e corte com tesoura) e a imersão em água fria promoveram a germinação das sementes. No entanto, os valores foram semelhantes, estatisticamente, à testemunha; a velocidade de germinação em laboratório foi maior quando as sementes foram escarificadas com lixa ou imersas em água fria por $2 \mathrm{~h}$; o tratamento com ácido sulfúrico (20 min) prejudicou o índice de velocidade de emergência em bandejas; os fungos detectados nas sementes foram Trichothecium $\mathrm{sp}$, Aspergillus sp, Cladosporium sp, Colletotrichum sp, Fusarium $\mathrm{sp}$., Penicillium sp e Rhizopus sp, mas não exerceram efeito na germinação e vigor das sementes.
\end{abstract}

Palavras-chave: Qualidade sanitária e espécie florestal.

\section{GERMINATION AND SANITY OF SEEDS OF Bauhinia variegata}

\begin{abstract}
SUMMARY - Bauhinia trees are considered late pioneers in plant succession, since they grow moderately fast. They can be used as grazing plants, ornamental, paper and cellulose, round log or sawn wood and also for recovery of degraded areas. Seeking alternatives for a faster and more uniform germination by means of scarification methods, Bauhinia variegata seeds were subjected to the following pre-germination treatments: mechanical scarification (sandpaper 220); immersion in hot water at $80^{\circ} \mathrm{C}$; immersion in cold water $\left(10^{\circ} \mathrm{C}\right.$ ) for 2 hours; scissors cuttings (area opposed to the micropyle); immersion in concentrated sulfuric acid for five minutes followed by washing in running water; immersion in concentrated sulfuric acid for 20 minutes followed by washing in running water. Seeds were then placed in plastic gerbox boxes with vermiculite substratum to germinate at $30^{\circ} \mathrm{C}$, evaluations were carried out on the $7^{\text {th }}$ and $14^{\text {th }}$ days. Seeds were also sown in trays
\end{abstract}

\footnotetext{
${ }^{1}$ Recebido em 12.07.2004 e aceito para publicação em 05.04.2006.

${ }^{2}$ Setor de Ciências Agrárias Departamento de Fitotecnia e Fitossaninaristo, Rua dos Funcionários da Universidade Federal do Paraná. 1540, 80035-50 Curitiba-PR. E-mail:<amseneme@ufpr.br>.

${ }^{3}$ Departamento de Fitotecnia e Fitossaninaristo da UFPR.

${ }^{4}$ Faculdade Francisco Maeda.
} 


\begin{abstract}
containing sand in the greenhouse. The parameters index of emergence speed and percent final emergence at 32 days after sowing were evaluated in greenhouse. Seed sanity was evaluated with 400 seeds using the Blotter test. Five sub-samples of 30 seeds from each treatment were used for the germination test and emergence speed index; the experiment was arranged in a complete randomized design and means were compared by the Tukey's Test $(P>0.05)$. Seed germination with mechanical scarification (with sandpaper and scissors cuttings) and immersion in cold water was no significantly different from the control; the germination speed in laboratory was higher when seeds were scarified with sandpaper or immerged in cold water for two hours; the treatment with sulfuric acid (20 minutes) impaired seedling emergence speed; Trichothecium $\mathbf{s p}$, Aspergillus $\mathbf{s p , ~ C l a d o s p o r i u m}$ sp, Colletotrichum sp, Fusarium sp., Penicillium sp and Rhizopus $\mathbf{s p}$ were the fungus species found in the seeds, however without affecting germination and vigor.
\end{abstract}

Keywords: sanitary quality and forest species.

\section{INTRODUÇÃO}

Bauhinia variegata é uma espécie exótica da família Caesalpinaceae, originária da Índia, conhecida vulgarmente como pata-de-vaca. A árvore é de porte médio, caducifólia e apresenta flores com coloração variegada (DURIGAN et al., 1997).

As árvores do Gênero Bauhinia distribuem-se pela zona tropical do mundo inteiro e podem ser utilizadas como plantas forrageira, ornamental, papel e celulose, madeira serrada e roliça e plantio de proteção. Espécies desse gênero são classificadas como pioneiras tardias na escala de sucessão vegetal, apresentando crescimento moderadamente rápido, e são utilizadas na recomposição vegetal, no reflorestamento de áreas degradadas e também na arborização de ruas (LORENZI, 1992).

As plantas dessa família apresentam sementes com dormência causada basicamente por um bloqueio físico representado pelo tegumento resistente e impermeável que, ao impedir a entrada de água e as trocas gasosas, não permite que o processo germinativo se inicie (LORENZI, 1992; ALVES et al., 2000). Alguns trabalhos com sementes do Gênero Bauhinia permitem essa afirmação. Sementes de B. fortificata apresentam germinação de 30 a $50 \%$, no entanto, quando escarificadas com ácido sulfúrico concentrado ou quando imersas em água quente $\left(80^{\circ} \mathrm{C}\right)$, a germinação chega a $80 \%$ (LORENZI, 1992).

Alves et al. (2000), estudando duas espécies do gênero Bauhinia, verificaram que os tratamentos mais eficientes para superar a dormência foram imersão em ácido sulfúrico durante $20 \mathrm{~min}$ para a $B$. monandra e a escarificação mecânica para $B$. ungulata. Segundo Carvalho (1994), sementes de B. fortificata não apresentam impermeabilidade à água como muitas leguminosas, mas dormência fisiológica; muitas sementes germinam sem tratamento pré-germinativo, porém a maioria delas necessita de tratamento que deve ser a imersão em água quente $\left(80^{\circ} \mathrm{C}\right)$ e permanência na água fora do aquecimento por 10 minutos, para embebição das sementes. Segundo aqueles autores, a melhor condição para a germinação é o uso de substrato vermiculita e temperatura de $30^{\circ} \mathrm{C}$. A imersão de sementes de B. bongardii em água fria durante duas horas antes da semeadura proporcionou germinação uniforme que ocorreu em torno de 10 a 20 dias e apresentou valores próximos de 80\% (DURIGAN et al., 1997)

As condições de temperatura e umidade do ambiente da floresta expõe a maioria das sementes de espécies florestais ao ataque de fungos; os reflexos de tal exposição são verificados não somente em campo, mas também no armazenamento. Diversos fungos podem causar deformação nas plântulas, redução na germinação, destruição das sementes e doenças em plantas. Os testes de sanidade possibilitam a identificação de problemas ocorridos durante as fases de colheita e armazenamento, permitindo estabelecer métodos de controle para esses patógenos. Alguns trabalhos foram conduzidos, verificando-se a presença de patógenos em sementes florestais (MARTINS NETO e FAIAD, 1985; CARVALHO e MUCHOVEJ, 1991; SILVA et al., 1999; SANTOS et al., 2003), mas há carência de informações disponíveis sobre o assunto.

O trabalho teve como objetivos avaliar a eficiência dos métodos de escarificação na germinação e emergência de plântulas de Bauhinia variegata e identificar os microrganismos potencialmente patogênicos ao desempenho fisiológico das sementes. 


\section{MATERIAL E MÉTODOS}

As sementes de Bauhinia variegata provenientes do Instituto de Pesquisa Florestal de Piracicaba, SP, no momento de seu recebimento estavam acondicionadas em embalagem plástica de polipropileno duplo. Logo após seu recebimento, determinou-se o teor de água e peso de 100 sementes, segundo prescrições descritas por Brasil (1992).

As sementes foram submetidas aos seguintes métodos de escarificação: escarificação mecânica (com lixa 220), imersão em água quente a $80^{\circ} \mathrm{C}$ e após permanência na mesma água fora do aquecimento durante 10 minutos (utilizaram-se $100 \mathrm{~mL}$ de água para 300 sementes); imersão em água fria $\left(10^{\circ} \mathrm{C}\right)$ durante duas horas (100 mL de água para 300 sementes); corte com tesoura (na região oposta à micrópila); imersão em ácido sulfúrico concentrado por cinco minutos seguida de lavagem em água corrente; imersão em ácido sulfúrico concentrado por 20 min seguida de lavagem em água corrente.

Em seguida, realizou-se a instalação do teste de germinação em caixas tipo gerbox, com substrato vermiculita (textura média), em germinador sob temperatura constante de $30^{\circ} \mathrm{C}$ (CARVALHO, 1994), e também efetuouse a semeadura em bandejas de isopor contendo areia esterilizada em casa de vegetação ( temperatura e umidade relativa do ar). O teste de germinação (em câmara a $30^{\circ} \mathrm{C}$ ) foi avaliado aos sete e 14 dias após a sua instalação, considerando-se germinadas aquelas sementes que apresentavam radícula com comprimento superior ou igual a $2 \mathrm{~mm}$; determinouse, ainda, a porcentagem de sementes mortas.

Em casa de vegetação, avaliaram-se o índice de velocidade de emergência (efetuando-se contagem a cada sete dias após o início da emergência) e a porcentagem final de emergência aos 32 dias após a semeadura em bandejas, ocasião em que o número de plantas por repetição tornou-se constante. Para cálculo do IVE (índice de velocidade de emergência), utilizou-se a fórmula IVE= $\mathrm{E}_{1} / \mathrm{N}_{1}+\mathrm{E}_{2} / \mathrm{N}_{2}+\ldots+\mathrm{E}_{\mathrm{n}} / \mathrm{N}_{\mathrm{n}}$, em que $\mathrm{E}_{1}, \mathrm{E}_{2} \ldots \mathrm{E}_{\mathrm{n}}$ representam o número de plântulas emergidas, computadas na primeira, segunda,..., última contagem, e $\mathrm{N}_{1}, \mathrm{~N}_{2}, \ldots \mathrm{N}_{\mathrm{n}}$ representam o número de dias da semeadura à primeira, segunda..., última contagem (NAKAGAWA, 1994).

O teste de sanidade foi realizado pelo método de papel-filtro com 400 sementes (quatro subamostras de 100 sementes), que consistiu na semeadura em papel filtro esterilizados e autoclavados em caixas tipo gerbox, em ambiente de sala previamente esterilizada, em regime de luz constante. Os fungos foram identificados com o auxílio de microscópio esteroscópio após a incubação de oito dias.

O delineamento experimental adotado foi inteiramente casualizado, com cinco subamostras de 30 sementes de cada tratamento, e a comparação entre as médias foi feita pelo teste de Tukey $(\mathrm{P}>0,05)$. Os dados em porcentagem foram transformados em arc sen $\sqrt{x}$, e, quando ocorreu o valor zero, a transformação foi em arc sen $\sqrt{ }(x+0,5)$; nas tabelas e figuras, os dados apresentados são originais.

\section{RESULTADOS E DISCUSSÃO}

Os resultados indicaram que os valores médios de peso e teor de água das sementes foram de 38,55 g e $8,9 \%$, respectivamente.

Valores estatisticamente semelhantes de germinação foram obtidos quando as sementes foram escarificadas com lixa, com tesoura e água fria, sendo a escarificação com ácido sulfúrico (20 minutos) e água quente os métodos que proporcionaram os menores valores de germinação (Quadro 1). Esses resultados diferem daqueles obtidos por Alves et al. (2000), que verificaram que sementes de B. monandra escarificadas em ácido sulfúrico durante o mesmo período tiveram germinação de $91 \%$, e o tratamento com água quente reduziu a germinação a zero. A imersão em água quente também causou diminuição drástica na germinação de sementes de B. ungulata (ALVES et. al., 2000).

Quadro 1 - Porcentagem de germinação (14 dias), primeira contagem de germinação (7 dias) e sementes mortas de B. variegata. Curitiba, 2003.

Table 1 - Percent germination (14 days), first germination count (7 days) and dead seeds of B. variegata. Curitiba, 2003

\begin{tabular}{lccc}
\hline Tratamentos & $\mathrm{G}(\%)^{1}$ & $\mathrm{PC}(\%)$ & $\mathrm{SM}(\%)$ \\
\hline Sementes intactas & $85 \mathrm{a}^{2}$ & $12 \mathrm{bc}$ & $1 \mathrm{c}$ \\
Lixa & $99 \mathrm{a}$ & $53 \mathrm{a}$ & $1 \mathrm{c}$ \\
Água quente & $28 \mathrm{c}$ & $2 \mathrm{c}$ & $63 \mathrm{a}$ \\
Água fria & $90 \mathrm{a}$ & $30 \mathrm{ab}$ & $4 \mathrm{c}$ \\
Corte com tesoura & $98 \mathrm{a}$ & $55 \mathrm{a}$ & $2 \mathrm{c}$ \\
$\mathrm{H}_{2} \mathrm{SO}_{4}$ (5 minutos) & $61 \mathrm{~b}$ & $34 \mathrm{ab}$ & $15 \mathrm{~b}$ \\
$\mathrm{H}_{2} \mathrm{SO}_{4}(20$ minutos) & $25 \mathrm{c}$ & $22 \mathrm{~b}$ & $66 \mathrm{a}$ \\
\hline $\mathrm{CV}(\%)$ & 12,56 & 26,13 & 20,95 \\
\hline
\end{tabular}

${ }^{1} \mathrm{G}(\%)$ : plântulas normais (14 dias); PC (\%): primeira contagem da germinação (7dias); e SM(\%): sementes mortas.

${ }^{2}$ Médias seguidas da mesma letra na coluna não diferem estatisticamente entre si, de acordo com o teste de Tukey $(\mathrm{P}>0,5)$.

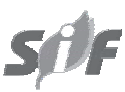

R. Árvore, Viçosa-MG, v.30, n.5, p.719-724, 2006 
A primeira contagem da germinação (PC) indicou que a escarificação com lixa e tesoura permitiu a emissão mais rápida da radícula, embora sem diferença significativa dos tratamentos com água fria e ácido sulfúrico (5 min). Sementes escarificadas com água quente tiveram desempenho semelhante ao da testemunha (sementes inteiras). A maior ocorrência de sementes mortas foi verificada quando se utilizou a escarificação com ácido (20 min) e água quente. O tratamento com água quente tem sido utilizado com sucesso para promover a germinação de sementes que apresentam impermeabilidade do tegumento, como as de Canna indica (GROOTJEM e BOUMAM, 1988) e Rhus javanica L. (WASHINGTON, 1988), porém as sementes de Bauhinia variegata submetidas ao tratamento com água quente apresentaram alta porcentagem de sementes mortas, diferindo significativamente dos demais tratamentos. Segundo Alves et al. (2000), em sementes de Bauhinia monandra esse tratamento foi totalmente ineficaz, impedindo sua germinação, provavelmente por causar dano ao embrião, e em sementes de B. ungulata houve redução significativa na germinação com relação às sementes sem tratamento

Os maiores índices de velocidade de emergência foram verificados nas sementes escarificadas com lixa, corte com tesoura e água fria, mas não diferiram significativamente daquelas tratadas com água quente e ácido sulfúrico por 5 min (Figura 1). Segundo trabalho conduzido por Lopes et al. (1999), a escarificação mecânica de sementes de B. variegata proporcionou maior vigor em relação aos demais tratamentos (água quente e ácido sulfúrico), mas não houve diferença significativa para a germinação total.

A emergência de plântulas em bandeja (Figura 2) foi prejudicada pela imersão das sementes em ácido sulfúrico (5 e 20 min), e embora não tenha ocorrido diferença significativa entre os demais tratamentos, a imersão em água fria foi o método que proporcionou maior porcentagem final de emergência (67\%); tais resultados são semelhantes àqueles obtidos por Durigan et al. (1997) em sementes de Bauhinia bongardii.

Por meio do Blotter Test foi possível a detecção dos fungos associados às sementes de Bauhinia variegata, que são apresentados na Figura 3. Os fungos de armazenamento dos gêneros Aspergillus e Penicillium apresentaram porcentagem de infecção de 7 e $4 \%$, respectivamente. Fungos desses gêneros podem afetar a germinação, causar perdas dos constituintes químicos essenciais e diminuir o crescimento das plântulas (GHOSH et al., 1981, citados por GHOSHI e NANDI, 1986).

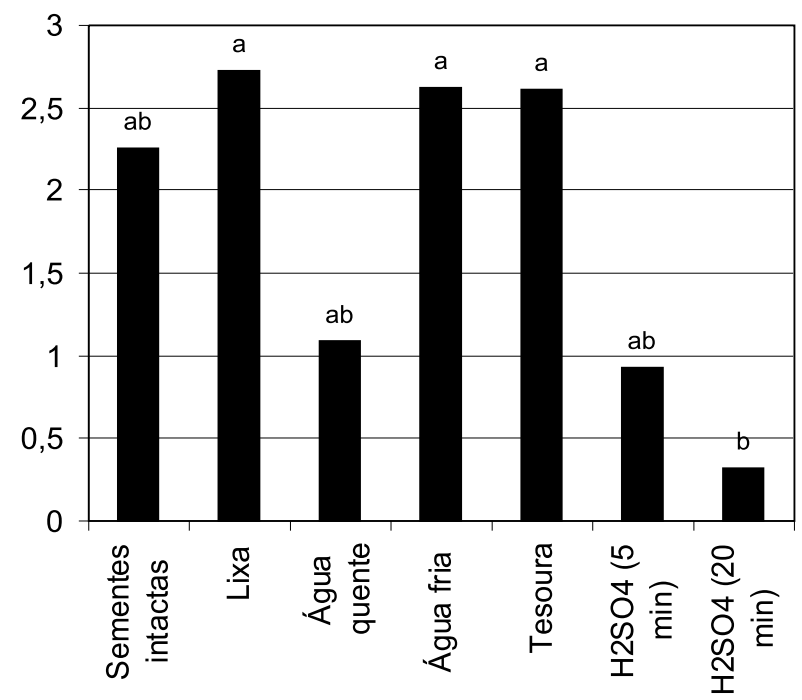

Figura 1 -Índice de velocidade de emergência (IVE) de plântulas de $B$. variegata em bandejas após os tratamentos para superar a dormência.

Figure 1 - Index of emergence speed (IVE) of seedlings in trays after treatments to overcome dormancy.

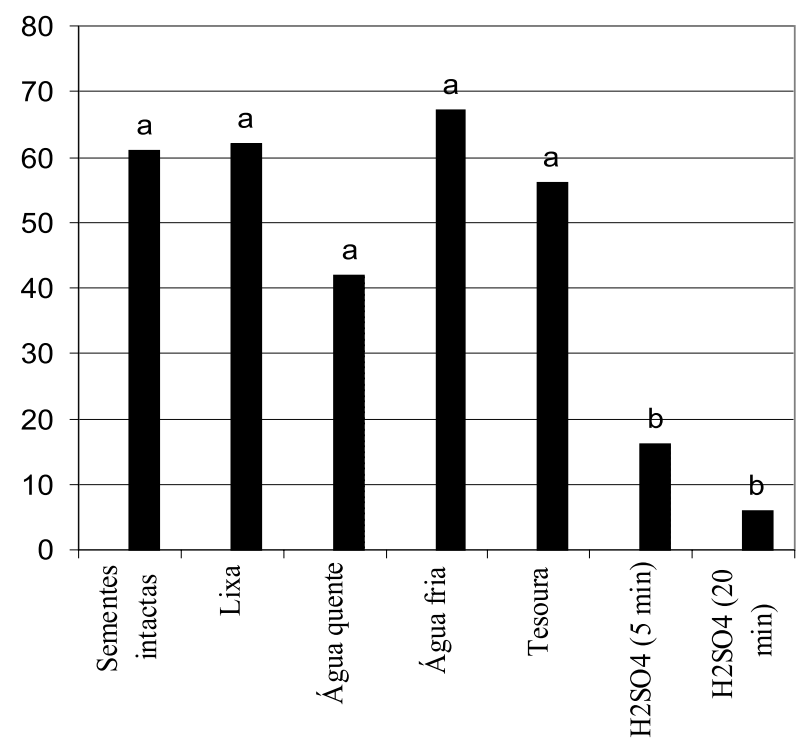

Figura 2 - Porcentagem final de emergência (EB) de plântulas de $B$. variegata em bandejas (EB) aos 32 dias após os tratamentos para superar a dormência.

Figure 2-Percent final emergence (EB) of B. variegata seedlings in trays 32 days after treatments to overcome dormancy. 


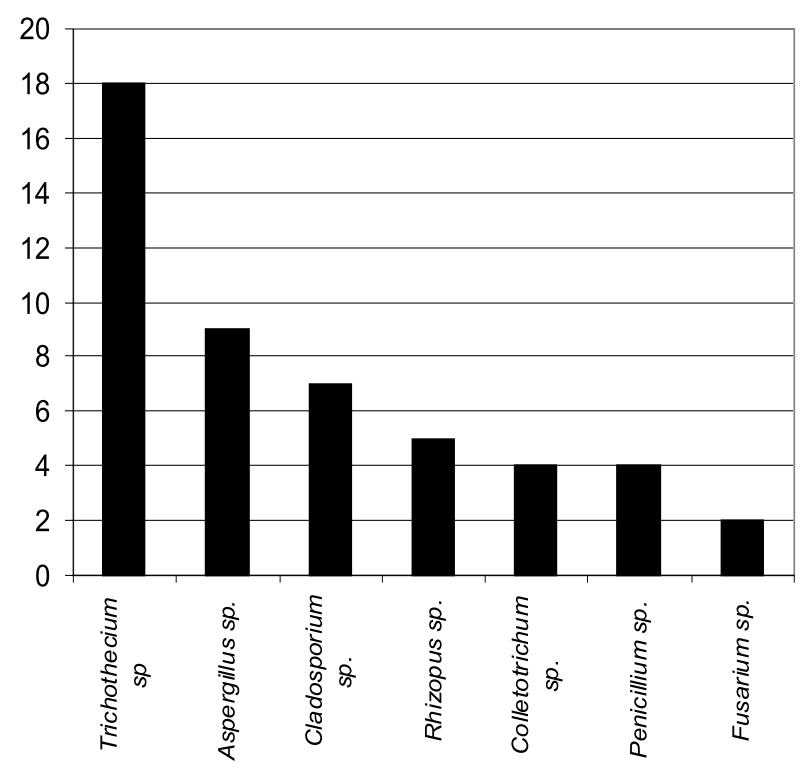

Figura 3 - Fungos detectados em sementes de Bauhinia variegata (Blotter Test). Curitiba, 2003.

Figure 3 -Fungus species found in seeds of Bauhinia variegata (Blotter Test).

Segundo Neergard (1997), os gêneros Fusarium, Phomopsis, Helmintosporium, Rhizoctonia, Colletotrichum e Cylindrocladium são patógenos responsáveis por mais de $90 \%$ de perda de sementes germinadas e de plântulas de espécies cultivadas. Em sementes de $B$.variegata foram encontrados dois dos gêneros citados por Neergard (1997), Colletotrichum sp. (4\%) e Fusarium sp. (2\%), no entanto, pouco se sabe sobre perdas econômicas significativas devido à presença de patógenos em sementes de espécies florestais. O gênero Trichothecium encontrado em $18 \%$ do total da amostra é classificado como saprófita ou parasita fraco (BARDNET e HUNTER, 1972)

A semente é o principal veículo de disseminação do gênero Colletotrichum que pode atuar causando tombamento de plântula ("damping off”) (MENTEN, 1991). Os gêneros Fusarium e Colletotrichum são comprovadamente patógenos de sementes de muitas espécies de plantas (CARVALHO e MUCHOVEJ, 1991) e podem ser responsáveis pela grande heterogeneidade na germinação das sementes (DHINGRA et al., 1980; SOAVE e WETZEL, 1987; MACHADO, 1988).

Detectou-se nas sementes de B. variegata a presença de Rhizopus em torno de 4,5\%. Em algodão, esse gênero é o principal responsável pela infecção de plântulas durante o teste de germinação. Quando apenas o sistema radicular foi emitido, o fungo ataca os cotilédones, apodrecendo-os antes de sua emergência, e quando o ataque é posterior ocorre o apodrecimento de toda a plântula (PATRICIO et al., 1991).

É necessário, além da realização de testes de patogenicidade, o acompanhamento do desempenho em viveiro para verificação dos possíveis danos causados por esses fungos na espécie $B$. variegata.

\section{CONCLUSÕES}

A escarificação mecânica (lixa e corte com tesoura) e a imersão em água fria promoveram a germinação das sementes, no entanto os valores foram semelhantes estatisticamente aos da testemunha.

A velocidade de germinação em laboratório foi maior quando as sementes foram escarificadas com lixa ou imersas em água fria por duas horas.

O tratamento com ácido sulfúrico (20 min) prejudicou o índice de velocidade de emergência das plântulas.

Os fungos detectados nas sementes foram Trichothecium sp, Aspergillus sp, Cladosporium sp, Colletotrichum sp, Fusarium sp., Penicillium sp e Rhizopus sp, mas não exerceram efeito na germinação e vigor das sementes.

\section{REFERÊNCIAS BIBLIOGRÁFICAS}

ALVES, M. C. S. et al. Superação da dormência em sementes de Bauhinia monadra Britt. e Bauhinia ungulata L. - Caesalpinoidea. Revista Brasileira de Sementes, v. 22, n. 2, p. 139-144, 2000.

BRASIL. Ministério da Agricultura e Reforma Agrária. Regras para análise de sementes. Brasília: 1992. 365p.

BARDNET, H.L.; HUNTER, B.B. Illustred genera of imperfect fungi. Minnesota: Burgess Publishing Company, 1972. 241p.

CARVALHO, W.L.; MUCHOVEJ, J.J. Fungos associados as sementes de essências florestais. Revista Árvore, v. 15, n. 2, p. 173-178, 1991. 
CARVALHO, P. E. R. Espécies florestais brasileiras: recomendações silviculturais, potencialidades e uso da madeira. Brasília: EMBRAPA-CNPF/SPI, 1994. 640p.

DHINGRA, O. D.; MUCHOVEJ, J.J; CRUZ FILHO, J. Tratamento de sementes. Controle de patógenos. Viçosa, MG: Universidade Federal de Viçosa, 1980. 607p.

DURIGAN, G. et al. Sementes e mudas de árvores tropicais. Campinas: Instituto Florestal, CINP/SMA, 1997.

GHOSH, J.; NANDI, B. Deteorative abilities of some common storage fungi of wheat. Seed Science and Tecnology, v. 14, p. 141-149, 1986.

GROOTJEM, C.J.; BOUMAM, F. Seedf struture in Canananceae: taxonomic and ecologycal implications. Annals of Botany, v. 61, n. 3, p. 363-371, 1988.

LORENZI, H. Árvores brasileiras. Manual de identificação e cultivo de plantas arbóreas nativas do Brasil. Nova Odessa: 1992. 352p.

LOPES, J.C.; CAPUCHO, M.T.; BARBOSA, L.G. Germinação de sementes de Bauhinia sp. -Fabaceae - Caesalpinoideae. In: CONGRESSO BRASILEIRO DE SEMENTES, 9., 1999, Foz do Iguaçu. Anais... Curitiba: 1999. p. 193.

MACHADO, J.C. Patologia de sementes: fundamentos e aplicações. Brasília: MEC, ESAL, FAEP, 1988. 106p.

MARTINS-NETTO, D.; FAIAD, M.G. R. Viabilidade e sanidade de sementes de espécies florestais. Revista Brasileira de Sementes, v. 17, n.1, p. 75-80, 1985.
MENTEN, J.O.M. Danos de patógenos em sementes. In: MENTEN, J.O.M. (Ed.) Patógenos em sementes: detecção, danos e controle químico. Piracicaba: Escola Superior de Agricultura Luiz de Queiroz, 1991. p. 115-136.

NAKAGAWA, J. Testes de vigor baseados na avaliação das plântulas. In: VIEIRA R. D., CARVALHO, N.M. Testes de vigor em sementes. Jaboticabal: FUNEP, 1994. p. 49-85.

NEEGARD, P. Seed pathology. London: Mac Millan Press, 1997. v. 2. 839 p.

PATRICIO, F.R.A.; BORIN, R.B.R.G; ORTOLANI, D.B. Patógenos associados à semente que reduzem a germinação e o vigor. In: MENTEN, J.O.M. (Ed.) Patógenos em sementes: detecção, danos e controle químico. Piracicaba: Escola Superior de Agricultura Luiz de Queiroz, 1991.p. 137-160.

SANTOS, A. F. et al. Fungos associados às sementes de vacum (Allophyllus edulis). In: CONGRESSO BRASILEIRO DE SEMENTES, 13., 2003, Curitiba. Anais... Curitiba: ABRATES, 2003. p. 225.

SILVA, P.P.; MONTEIRO, P.P.M.; FAIAD, M.G.R. Fungos em sementes de espécies nativas do cerrado. In: CONGRESSO BRASILEIRO DE SEMENTES, 11., 1999, Foz do Iguaçu. Anais...Curitiba: 1999. p. 104.

SOAVE, J.; WETZEL, M.M.V.S. Patologia de sementes. Campinas: Fundação Cargill, 1987. 480p.

WASHINGTON, I. Effect of high temperature of permeability and germinability of the hard seeds of Rhus javanica. Annals of Botany, v. 62, n. 1, p. 13-6, 1988. 